\title{
Factors Related to Coronary Heart Disease Risk Among Men: Validation of the Framingham Risk Score
}

\author{
Jennifer Gander, MSPH; Xuemei Sui, MD, MPH, PhD; Linda J Hazlett, PhD; Bo Cai, PhD; \\ James R. Hébert, ScD; Steven N. Blair, PED
}

\begin{abstract}
Suggested citation for this article: Gander J, Sui X, Hazlett LJ, Cai B, Hébert JR, Blair SN. Factors Related to Coronary Heart Disease Risk Among Men: Validation of the Framingham Risk Score. Prev Chronic Dis 2014;11:140045. DOI: http://dx.doi.org/ 10.5888/pcd11.140045.
\end{abstract}

\section{PEER REVIEWED}

\section{Abstract}

\section{Introduction}

Coronary heart disease (CHD) remains a leading cause of death in the United States. The Framingham Risk Score (FRS) was developed to help clinicians in determining their patients' CHD risk. We hypothesize that the FRS will be significantly predictive of CHD events among men in the Aerobics Center Longitudinal Study (ACLS) population.

\section{Methods}

Our study consisted of 34,557 men who attended the Cooper Clinic in Dallas, Texas, for a baseline clinical examination from 1972 through 2002. CHD events included self-reported myocardial infarction or revascularization or death due to CHD. During the 12year follow-up 587 CHD events occurred. Multivariable-adjusted hazard ratios generated from ACLS analysis were compared with the application of FRS to the Framingham Heart Study (FHS).

\section{Results}

The ACLS cohort produced similar hazard ratios to the FHS. The adjusted Cox proportional hazard model revealed that men with total cholesterol of $280 \mathrm{mg} / \mathrm{dL}$ or greater were 2.21 (95\% confidence interval (CI), 1.59-3.09) times more likely to have a CHD event than men with total cholesterol from 160 through $199 \mathrm{mg} / \mathrm{dL}$; men with diabetes were 1.63 (95\% CI, 1.35-1.98) times more likely to experience a CHD event than men without diabetes.

\section{Conclusion}

The FRS significantly predicts CHD events in the ACLS cohort. To the best of our knowledge, this is the first report of a large, single-center cohort study to validate the FRS by using extensive laboratory and clinical measurements.

\section{Introduction}

Coronary heart disease (CHD) remains one of the leading causes of death in the United States, accounting for approximately 17\% of overall national health care expenditures (1). CHD is the accrual of plaque in the arteries of the heart (2) that supply the blood for maintaining normal cardiac function. The accumulation of plaque narrows the heart's arteries and reduces blood flow to the heart muscle. The lack of oxygen-rich blood to portions of the heart muscle leads to ischemia of myocardial tissues and consequent alteration of heart function. CHD also can be caused by the deposition of fat beneath the endothelium, reducing the elasticity of arteries (2). This arterial damage is caused by an array of significant risk factors such as hypertension (3), hypercholesterolemia (4), diabetes (5), and smoking (6). However, these risk factors are modifiable through individual and population-level behavior change; through close monitoring of cholesterol, blood glucose, and other risk factors; and by treating any of these risk factors that are above acceptable ranges with medication such as statins or insulin. As a result, many countries have experienced a decrease of CHD incidence in the past 30 years (7).

Several risk scores have been developed to provide guidance to clinicians on their patients' risk for CHD $(8,9)$. The Framingham Risk Score (FRS) $(9,10)$ is the CHD risk score most widely used by clinicians across the globe (11). The FRS originated from the Framingham Heart Study (FHS), a relatively homogeneous cohort residing in Framingham, Massachusetts (9), and has been applied and validated in a variety of different populations $(12,13)$. However, the study of Kagan et al (13) lacked complete congru- 
ency with FRS methodology, and other studies such as those of Lee et al (12) and Fried et al (14) had relatively small sample sizes. A recent publication updated the 1998 FRS and developed a new risk score that predicted an individual's cardiovascular disease risk instead of the CHD outcome (15). For this study, we chose to investigate CHD outcomes as they comprise the majority of cardiovascular disease events (16).

Our research aims to expand on recent validation studies (17) that used the Aerobics Center Longitudinal Study (ACLS) cohort and the measured outcome of 10 -year risk for CHD. ACLS provides a larger cohort to validate FRS than FHS or other previous studies, and FRS has yet to be applied to this cohort. Extensive measures of FRS components and CHD outcomes are available on the more than 40,000 participants (18) in the ACLS cohort. Our objective was to test the hypothesis that the FRS will be significantly predictive of CHD events among men in the ACLS population.

\section{Methods}

\section{Study population}

ACLS is an observational longitudinal study whose members were patients of the Cooper Clinic, Dallas, Texas, where they received a preventive medical examination and counseling on health behaviors during periodic visits. The Cooper Clinic serves anyone who elects to come for an examination, and patients come from all 50 states. During the patients' medical examination, they were informed of the ACLS, asked to participate, and if they agreed to participate, they consented to follow-up surveillance. The ACLS protocol was annually reviewed and approved by the Cooper Institute's institutional review board.

Participants were examined at least once from 1972 through 2002 at the Cooper Clinic. The cohort consisted mostly of patients in the middle and high socioeconomic groups: approximately $80 \%$ had college degrees (19). The mean baseline age of the cohort was 42 years (20) and consisted mostly of men (75\%) and non-Hispanic whites $(>95 \%)$.

Although ACLS is not a representative sample of the entire US population, a comparison of median values of specific physiological variables show similarity to representative population data (21).

A large number of women were enrolled in ACLS $(n=11,276)$; however, women were excluded from this analysis because of the small number of CHD events $(n=45)$ during the follow-up period. The following inclusion criteria were applied to the ACLS cohort participants for the current study: 1) age at baseline examination from 30 to 74 years, 2) complete data for outcome and predictor variables, and 3) free of CHD diagnosis or cancer diagnosis at baseline. To control for any unmeasured confounders that may have caused early drop-out, men with less than 1 year of follow-up were excluded from the study's cohort (Figure 1).

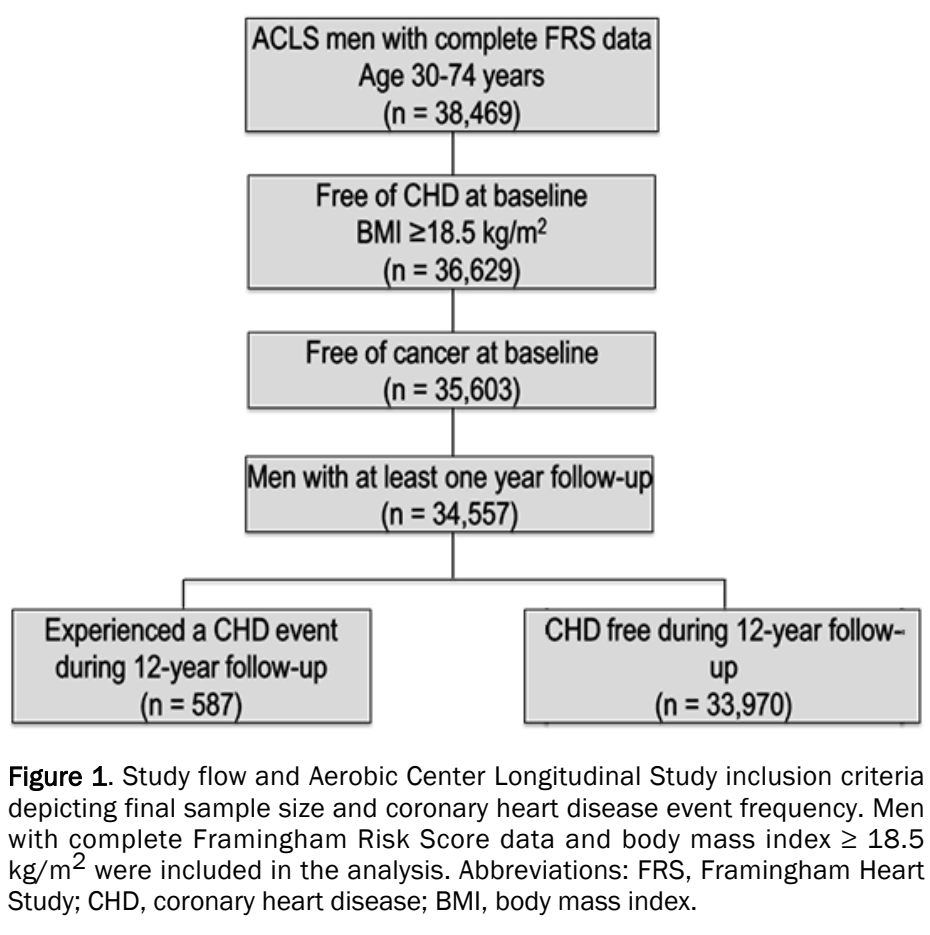

\section{Clinical examination}

Trained technicians followed standardized protocols in conducting each measurement. The baseline clinical examination included a personal and family medical history, anthropometric measurements, a 12-hour fasting blood chemistry including glucose and cholesterol measurements, electrocardiogram, blood pressure assessment, and a maximal exercise test $(21,22)$.

CHD was the primary end point being investigated. CHD was defined as the self-report of myocardial infarction or revascularization (including, bypass, coronary balloon, angioplasty, or stent) or death due to CHD. Participants reported their history of infarction or revascularization and incident date through a mail-back questionnaire administered in 1982, 1986, 1990, 1995, 1999, and 2004. Deaths among study participants were identified from the National Center for Health Statistic's National Death Index. International Classification of Disease (ICD), Ninth Revision, codes 410.0-414.0 and Tenth Revision, codes I20-I25, were used to identify CHD as the primary cause of death. According to the FRS follow-up time definition, the maximal follow-up time was 12

The opinions expressed by authors contributing to this journal do not necessarily reflect the opinions of the U.S. Department of Health and Human Services, the Public Health Service, the Centers for Disease Control and Prevention, or the authors' affiliated institutions. 
years. The 12-year follow-up was used in the regression and survival analysis and then adapted to provide 10-year CHD incidence estimates.

The covariates considered for analyses in the ACLS population mimicked the variables included in the recently updated FRS (10). Hypertension was divided into 4 categories according to systolic blood pressure and diastolic blood pressure. Systolic blood pressure was categorized into 4 levels: $<130 \mathrm{~mm} \mathrm{Hg}, 130-139 \mathrm{~mm}$ $\mathrm{Hg}, 140-159 \mathrm{~mm} \mathrm{Hg}$, or $\geq 160 \mathrm{~mm} \mathrm{Hg}$, and diastolic blood pressure was categorized into 4 levels: $<85 \mathrm{~mm} \mathrm{Hg}, 85-89 \mathrm{~mm} \mathrm{Hg}$, 90-99 $\mathrm{mm} \mathrm{Hg}$, and $\geq 100 \mathrm{~mm} \mathrm{Hg}$. When an participant's blood pressure fell into different categories for systolic and diastolic blood pressure, the higher category was chosen for categorization. For example, if a participant's blood pressure was 130/80 (systolic blood pressure/diasystolic blood pressusre), the corresponding categories for systolic blood pressure would be 2, and the diastolic blood pressure category would be 1 . To determine the hypertension category, the higher classification would be chosen and the hypertension categorization would be 2 in this example. Hypertension definition was made without regard to a participant's use of antihypertensive medications. The definition of hypertension parallels the FRS definition (10).

Total cholesterol was grouped into four levels: $<200 \mathrm{mg} / \mathrm{dL}$, 200-239 mg/dL, 240-279 mg/dL, and $\geq 280 \mathrm{mg} / \mathrm{dL}$. High-density lipoprotein was categorized as: $<35 \mathrm{mg} / \mathrm{dL}, 35-59 \mathrm{mg} / \mathrm{dL}$, and $\geq$ $60 \mathrm{mg} / \mathrm{dL}$. A 12-hour fasting glucose $>140 \mathrm{mg} / \mathrm{dL}$ classified an individual as having diabetes. Smoking status was dichotomized as current smoker or nonsmoker. All categorizations and definitions were analogous to FRS covariate groupings (10).

\section{Statistical analysis}

Descriptive statistics were generated to compare the ACLS population with the FRS population. Men in each cohort were compared on mean age; percentage within each category in hypertension, total cholesterol, and HDL; percentage with diabetes, and percentage of current smokers. Univariate Cox Proportional Hazard models were performed for the CHD events and each covariate to determine each characteristic's predictive power. Cox Survival analyses were conducted to determine the 10-year CHD risk for the ACLS male population. The fully adjusted Cox Proportional Hazard model included age, blood pressure, total cholesterol, high density lipoprotein cholesterol, diabetes diagnosis, and smoking status.

Predictive accuracy was determined through the concordance statistic (C statistic) associated with the receiver operating characteristic (ROC) curve. The ROC curve measures the discrimination power of these diagnostic markers for the CHD outcome. The
Hosmer-Lemeshow statistic is used to assess calibration and is a $\chi^{2}$ test calculated by sorting the sample by estimated probability of success (23). The higher the $\mathrm{C}$ statistic, the better the prediction. A limitation of the Hosmer-Lemeshow test is that it is not recommended for sample sizes larger than 25,000. A sensitivity analysis was performed following the recommendations of Paul et al (23), and the ACLS sample $(\mathrm{n}=34,557)$ and a smaller 10,000 sample cohort were randomly selected. To satisfy this limitation, the Hosmer-Lemeshow test was performed on a randomly selected cohort $(\mathrm{n}=10,000)$, and $P$ value of $P>.05$ represents no significant difference between predicted and observed events. All analyses were performed using SAS version 9.3.

\section{Results}

During the 12-year follow-up period (284,572 person-years of exposure), 587 men had a CHD event. The incidence rate was 20 per 10,000 person-years. The ACLS cohort had approximately 32,000 more participants (Table 1) than the FHS, and participants were, on average, younger $(P<.001)$. FHS had a higher proportion of people with diabetes $(5.0 \%)$ and smokers $(40.0 \%)$ than the ACLS cohort, which had $1.5 \%$ and $17.0 \%$, respectively $(P<.001)$ (Table 1).

When the ACLS cohort is stratified by CHD status, men who experienced a CHD event during the 12-year follow-up were significantly different on all predictor variables; that is, they were older, had higher blood pressure, and were in the top 2 categories for high-density lipoprotein cholesterol. Among those men who experienced CHD during follow-up, $4.6 \%$ had diabetes and $23.3 \%$ were smokers compared with $1.47 \%(P<.001)$ with diabetes and $16.8 \%$ current smokers $(P<.001)$ who did not experience CHD (Table 2).

The covariates based on the FRS were all significant when applied to the men in ACLS (Table 3). The hazard ratios (HRs) reported from FHS by D'Agostino et al (2001) (17) were similar to the ACLS fully adjusted HRs. The fully adjusted HRs show that men with Stage I hypertension ( $\mathrm{HR}=1.41 ; 95 \%$ confidence interval $[\mathrm{CI}], 1.16-1.72$ ) have significantly higher risk of CHD than men with optimal or normal blood pressure. Men with total cholesterol at or greater than $280 \mathrm{mg} / \mathrm{dL}$ were more than twice (HR, 2.21; 95\% CI, 1.59-3.09) as likely to have a CHD event than men with total cholesterol between 160 and $199 \mathrm{mg} / \mathrm{dL}$. Men with diabetes were 1.82 (95\% CI, 1.23-2.70) times more likely to experience a CHD event than men without diabetes. Current smokers also had a significantly higher risk (HR, 1.63; 95\% CI, 1.35-1.98) for CHD than nonsmokers during the 12-year follow-up.

The opinions expressed by authors contributing to this journal do not necessarily reflect the opinions of the U.S. Department of Health and Human Services, the Public Health Service, the Centers for Disease Control and Prevention, or the authors' affiliated institutions. 
The $\mathrm{C}$ statistic (area under the curve) obtained from the receiver operating characteristic (ROC) curve was 0.7697 (95\% CI, 0.7523-0.7871) (Figure 2). The Hosmer-Lemeshow test reported no significant lack of fit for the model ( $P=.88$ ), and we failed to reject the null hypothesis that states there is no significant difference between the predicted and observed values of the outcome variable.

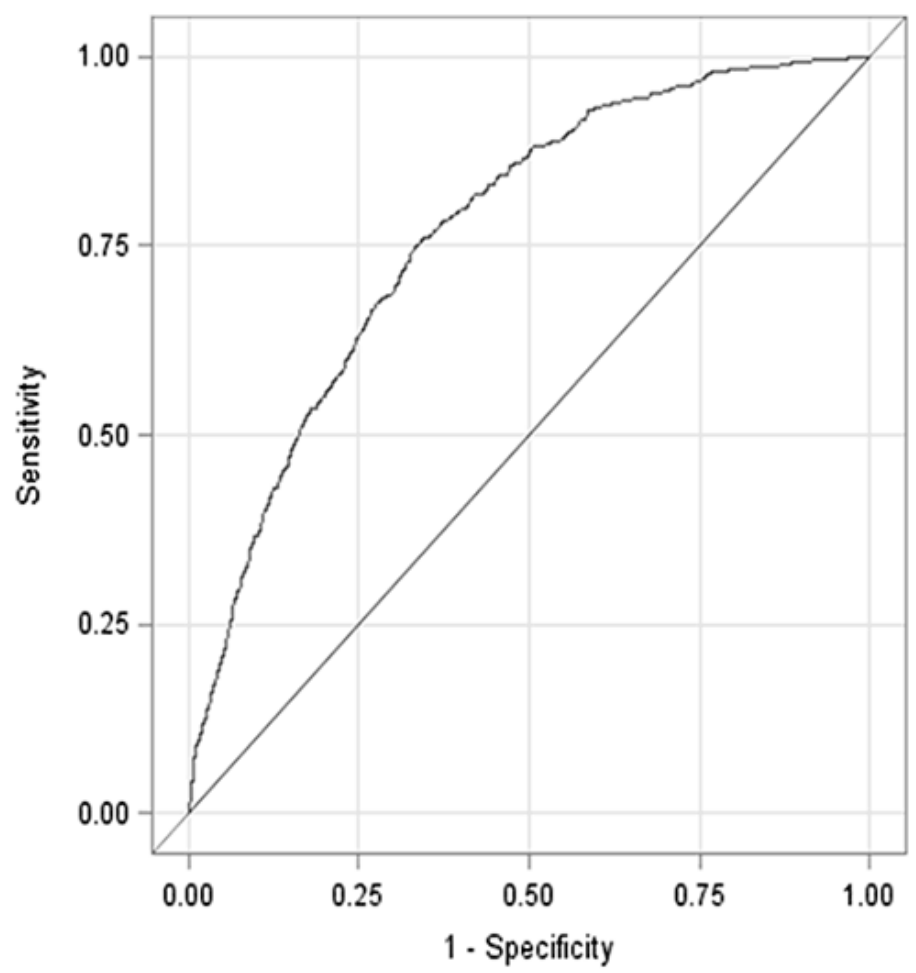

Figure 2. Receiver operating characteristic curve representing the predictive ability of the Framingham Risk Score applied to the Aerobics Center Longitudinal Study cohort after a 12-year follow-up. The Hosmer-Lemeshow C statistic is represented by the Area Under the Curve (C $=0.7697,95 \%$ confidence interval, 0.7523-0.7871).

\section{Discussion}

The FRS significantly predicts CHD events occurring during the 12-year follow-up in the ACLS, which was a much larger study than the original FHS. In addition to our main finding, we also found that age, blood pressure, total cholesterol, high-density lipoprotein cholesterol, diabetes diagnosis, and smoking status were associated with CHD events. The relative risks were congruent with the those reported from the FHS (17) and previous studies $(12,13)$.
Elevated blood pressure creates more strain for the heart, which can cause stiffness of the heart muscle (2) or create microscopic tears in the walls that may develop into scar tissue (2). Myocardial ischemia is common among patients with hypertension $(3,5)$, and reports from the FHS showed that hypertension was the primary cause of congestive heart failure in $35 \%$ of cases (24). Men with diabetes are also at increased risk for CHD (25), and additional research shows that people with both diabetes and hypertension have a higher incidence of heart disease than people with diabetes or hypertension alone (5).

Doyle et al published the findings of a study that examined the association between smoking and CHD (26) in two prospective studies: The FHS and the cohort from the Albany, New York, civil service study, with a combined study population of over 1,800 men without CHD (26). The Doyle et al study concluded that men with elevated systolic blood pressure and elevated total cholesterol who smoked were at a $1.8(P<.05)$ times higher risk of premature mortality than men with elevated systolic blood pressure and elevated total cholesterol who did not smoke (26). Our findings are also in line with the Physicians' Health Study, which reported significant effects of HDL cholesterol and total cholesterol on CHD (17).

Other researchers investigated FRS's predictability in various populations. The Honolulu Heart Study began in 1965 with the overall goal of standardizing cardiovascular examinations (13). The cohort comprised Japanese American men born between 1900 and 1919 whose data were updated with information from their World War II Selective Service files; the final population comprised approximately 8,000 men free of CHD on baseline examination at study initiation (13). Cigarette smoking, cholesterol levels, blood pressure, sum of arm and back skinfold measurements, and uric acid levels were significant predictors of CHD; however, glucose intolerance showed no significant relationship to CHD. The lack of congruency in the significant results between the Honolulu Heart Study, FHS, and ACLS may be due to the Honolulu Heart Study population being at low risk of CHD (ie, CHD incidence observed in the Honolulu Study was about half that of the FHS).

To the best of our knowledge, this is the first large, single-center, prospective cohort to validate the FRS with the same level of precision as that of the FHS. The present study expands on previous research through the improvement of internal validity by using objectively measured clinical data.

A limitation of the ACLS cohort (similar to an FHS limitation) is the homogeneity of the study population's sociodemographic factors. This limitation was explored through comparison analysis between ACLS and 2 large population-based cohorts; ACLS res-

\footnotetext{
The opinions expressed by authors contributing to this journal do not necessarily reflect the opinions of the U.S. Department of Health and Human Services, the Public Health Service, the Centers for Disease Control and Prevention, or the authors' affiliated institutions.
} 
ults were found to be similar to the results of the Lipid Research Clinics Prevalence Survey and the Canada Fitness Survey (27). It should be noted that ACLS homogeneity may be a strength because it improves internal validity by controlling for potential demographic confounders such as education, socioeconomic status, and race/ethnicity; however, generalizations must be made cautiously, and future research should be conducted on more diverse populations. Unlike the FHS finding, the ACLS found that having stage II-IV hypertension was not significantly associated with CHD, which may be due to the small proportion (4.93\%) of the ACLS's cohort who were in this group.

Although CHD remains one of the leading causes of death in the United States, the prevalence of CHD has decreased since 2004 (28), a reduction that can be largely attributed to better medical treatment and improvement in CHD risk profiles. The FRS was developed to assist clinicians in estimating their patients' absolute risk for CHD (17). This study further evaluates FRS performance in the larger ACLS cohort and strictly followed the FHS methodology, which does not control for other CHD risk factors such selfrated health status (29), family history of CHD (30), and cardiorespiratory fitness (18). Future research should focus on expanding the FRS to include other modifiable risk factors. Community interventions and education programs should continue to target these CHD risk factors to further the prevention of heart disease.

\section{Acknowledgments}

Preparation of this article was supported by National Institutes of Health, grants AG06945, HL62508, and DK088195. The content is solely the responsibility of the authors and does not necessarily represent the official views of the National Institutes of Health. We thank the Cooper Clinic physicians and technicians for collecting the baseline data, and staff at the Cooper Institute for data entry and data management. The authors report no conflicts of interest.

\section{Author Information}

Corresponding Author: Xuemei Sui, University of South Carolina, 921 Assembly Street, Rm 226, Columbia, SC 29208. Telephone: 803-777-3881. E-mail: msui@mailbox.sc.edu.

Author Affiliations: Jennifer Gander, Linda J Hazlett, Bo Cai, James R. Hébert, Steven N. Blair, University of South Carolina, Columbia, South Carolina.

\section{References}

1. Lloyd-Jones D, Adams RJ, Brown TM, Carnethon M, Dai S, De Simone G, et al. Heart disease and stroke statistics - 2010 update: a report from the American Heart Association. Circulation 2010;121(7):e46-e215. Erratum in: Circulation. 2010 Mar 30;121(12):e260. Stafford, Randall [corrected to Roger, Véronique L]. Circulation. 2011 Oct 18;124(16):e425.

2. Coronary Heart Disease. American Heart Association; 2013. http://www.heart.org/HEARTORG/Conditions/More/ MyHeartandStrokeNews/Coronary-Artery-Disease - TheABCs-of-CAD_UCM_436416_Article.jsp. Accessed December 20, 2013.

3. Strauer B-E. Myocardial oxygen consumption in chronic heart disease: role of wall stress, hypertrophy, and coronary reserve. Am J Cardiol 1979;44(4):730-40.

4. Wijeysundera HC, Machado M, Farahati F, Wang X, Witteman W, van der Velde G, et al. Association of temporal trends in risk factors and treatment uptake with coronary heart disease mortality, 1994-2005. JAMA 2010;303(18):1841-7.

5. Grossman E, Messerli FH. Diabetic and hypertensive heart disease. Ann Intern Med 1996;125(4):304-10.

6. Scheidt S. Changing mortality from coronary heart disease among smokers and nonsmokers over a 20 -year interval. Prev Med 1997;26(4):441-6.

7. Bennett K, Kabir Z, Unal B, Shelley E, Critchley J, Perry I, et al. Explaining the recent decrease in coronary heart disease mortality rates in Ireland, 1985-2000. J Epidemiol Community Health 2006;60(4):322-7.

8. Assmann G, Schulte H. The Prospective Cardiovascular Münster (PROCAM) study: prevalence of hyperlipidemia in persons with hypertension and/or diabetes mellitus and the relationship to coronary heart disease. Am Heart J 1988;116(6 Pt 2):1713-24.

9. Kannel WB, McGee D, Gordon T. A general cardiovascular risk profile: the Framingham Study. Am J Cardiol 1976; 38(1):46-51.

10. Wilson PW, D'Agostino RB, Levy D, Belanger AM, Silbershatz H, Kannel WB. Prediction of coronary heart disease using risk factor categories. Circulation 1998; 97(18):1837-47.

11. Sposito AC, Ramires JA, Jukema JW, Molina JC, da Silva PM, Ghadanfar MM, et al.. Physicians' attitudes and adherence to use of risk scores for primary prevention of cardiovascular disease: cross-sectional survey in three world regions. Curr Med Res Opin 2009;25(5):1171-8.

The opinions expressed by authors contributing to this journal do not necessarily reflect the opinions of the U.S. Department of Health and Human Services, the Public Health Service, the Centers for Disease Control and Prevention, or the authors' affiliated institutions. 
12. Lee ET, Welty TK, Fabsitz R, Cowan LD, Le N-A, Oopik AJ, et al. The Strong Heart Study. A study of cardiovascular disease in American Indians: design and methods. Am J Epidemiol 1990;132(6):1141-55.

13. Kagan A, Gordon T, Rhoads GG, Schiffman JC. Some factors related to coronary heart disease incidence in Honolulu Japanese men: the Honolulu Heart Study. Int J Epidemiol 1975;4(4):271-9.

14. Fried LP, Borhani NO, Enright P, Furberg CD, Gardin JM, Kronmal RA, et al. The cardiovascular health study: design and rationale. Ann Epidemiol 1991;1(3):263-76.

15. D'Agostino RBSr, Vasan RS, Pencina MJ, Wolf PA, Cobain M, Massaro JM, et al. General cardiovascular risk profile for use in primary care. Circulation 2008;117(6):743-53.

16. Go AS, Mozaffarian D, Roger VL, Benjamin EJ, Berry JD, Borden WB, et al. Heart disease and stroke statistics-2013 update: a report from the American Heart Association. Circulation 2013;127(1):e6.

17. D'Agostino RBSr, Grundy S, Sullivan LM, Wilson P. Validation of the Framingham coronary heart disease prediction scores. JAMA 2001;286(2):180-7.

18. Blair SN, Cooper KH, Gibbons LW. Physical fitness and allcause mortality of healthy men and women. JAMA 1989; 262(17):2395-401.

19. Kampert JB, Blair SN, Barlow CE, Kohl HW. Physical activity, physical fitness, and all-cause and cancer mortality: a prospective study of men and women. Ann Epidemiol 1996; 6(5):452-7.

20. Sui X, Hooker SP, Lee I-M, Church TS, Colabianchi N, Lee C$\mathrm{D}$, et al. A prospective study of cardiorespiratory fitness and risk of type 2 diabetes in women. Diabetes Care 2008; 31(3):550-5.

21. Blair SN, Kannel WB, Kohl HW, Goodyear N, Wilson PW. Surrogate measures of physical activity and physical fitness evidence for sedentary traits of resting tachycardia, obesity, and low vital capacity. Am J Epidemiol 1989;129(6):1145-56.

22. Blair SN, Kampert JB, Kohl HW3d, Barlow CE, Macera CA, Paffenbarger RSJr, et al. Influences of cardiorespiratory fitness and other precursors on cardiovascular disease and all-cause mortality in men and women. JAMA 1996;276(3):205-10.

23. Paul P, Pennell ML, Lemeshow S. Standardizing the power of the Hosmer-Lemeshow goodness of fit test in large data sets. Stat Med 2013;32(1):67-80.

24. Kannel WB, Castelli WP, McNamara PM, McKee PA, Feinleib M. Role of blood pressure in the development of congestive heart failure. The Framingham study. N Engl J Med 1972;287(16):781-7
25. Haffner SM, Lehto S, Rönnemaa T, Pyörälä K, Laakso M. Mortality from coronary heart disease in subjects with type 2 diabetes and in nondiabetic subjects with and without prior myocardial infarction. N Engl J Med 1998;339(4):229-34.

26. Doyle JT, Dawber TR, Kannel WB, Kinch SH, Kahn HA. The relationship of cigarette smoking to coronary heart disease. JAMA 1964;190(10):886-90.

27. Sui X. Longitudinal analyses of physical activity and cardiorespiratory fitness on adiposity and glucose levels. ProQuest Dissertations and Theses. 2012;126.

28. Lloyd-Jones DM, Hong Y, Labarthe D, Mozaffarian D, Appel LJ, Van Horn L, et al. Defining and setting national goals for cardiovascular health promotion and disease reduction: the American Heart Association's strategic impact goal through 2020 and beyond. Circulation 2010;121(4):586-613.

29. Gander J, Lee D-c, Sui X, Hébert JR, Hooker SP, Blair SN. Self-rated health status and cardiorespiratory fitness as predictors of mortality in men. Br J Sports Med 2011; 45(14):1095-100.

30. Brown WM, Beck SR, Lange EM, Davis CC, Kay CM, Langefeld $\mathrm{CD}$, et al. Age-stratified heritability estimation in the Framingham Heart Study families. BMC Genet 2003; 4(Suppl 1):S32.

\footnotetext{
The opinions expressed by authors contributing to this journal do not necessarily reflect the opinions of the U.S. Department of Health and Human Services, the Public Health Service, the Centers for Disease Control and Prevention, or the authors' affiliated institutions.
} 


\section{Tables}

Table 1. Comparison Between Demographic Characteristics of Men Free of Coronary Vascular Disease at Baseline in the Framingham Heart Study (FHS) and the Aerobics Center Longitudinal Study (ACLS) ${ }^{\mathrm{a}}$

\begin{tabular}{|c|c|c|}
\hline \multirow[t]{2}{*}{ Risk Factor } & \multicolumn{2}{|c|}{ Study Comparison ${ }^{b}$} \\
\hline & $\mathrm{FHS}^{\mathrm{c}}(\mathrm{n}=2,439)$ & $\operatorname{ACLS}(n=34,557)$ \\
\hline Age range, $y$ & $30-74$ & $30-74$ \\
\hline Mean age, y & 48.30 & 44.82 \\
\hline \multicolumn{3}{|l|}{ Blood pressure, $(\mathrm{mm} \mathrm{Hg})$} \\
\hline Optimal and normal (SBP <130, DBP <85) & 44.00 & 59.85 \\
\hline High normal (SBP 130-139, DBP 85-89) & 20.00 & 16.24 \\
\hline Stage I hypertension (SBP 140-159, DBP 90-99) & 23.00 & 18.98 \\
\hline Stage II-IV hypertension (SBP $\geq 160, \mathrm{DBP} \geq 100$ ) & 13.00 & 4.93 \\
\hline \multicolumn{3}{|l|}{ Total cholesterol (mg/dL) } \\
\hline$<160$ & 7.00 & 9.34 \\
\hline $160-199$ & 31.00 & 34.36 \\
\hline $200-239$ & 39.00 & 36.67 \\
\hline $240-279$ & 17.00 & 15.10 \\
\hline$\geq 280$ & 6.00 & 4.53 \\
\hline \multicolumn{3}{|l|}{ High-density lipoprotein cholesterol (mg/dL) } \\
\hline$<35$ & 19.00 & 16.24 \\
\hline $35-59$ & 70.00 & 70.97 \\
\hline$\geq 60$ & 11.00 & 12.79 \\
\hline Diabetes & 5.00 & 1.52 \\
\hline Current smoker & 40.00 & 16.95 \\
\hline
\end{tabular}

Abbreviations: SBP, systolic blood pressure; DBP, diastolic blood pressure.

a Numbers are expressed as percentages unless otherwise stated.

${ }^{\mathrm{b}}$ Independent $t$ test was used to determine statistically significant difference in age between FHS and ACLS participants; proportion test calculated the statistical difference for each level of blood pressure, total cholesterol, high-density lipoprotein cholesterol, diabetes, and current smoking between FHS and ACLS participants. All proportion tests were significant with a $P$ value $<.001$.

${ }^{\mathrm{C}}$ FHS, Framingham Risk Score descriptive statistics referenced from D'Agostina et al (17). 
Table 2. Comparison Between Demographic Characteristics of Men With and Without a Coronary Heart Disease (CHD) Event in the Aerobic Center Longitudinal Study (ACLS) ${ }^{\mathrm{a}}$

\begin{tabular}{|c|c|c|}
\hline \multirow[t]{2}{*}{ RISK FACTOR } & \multicolumn{2}{|c|}{ CHD Event Comparison within ACLS ${ }^{b}$} \\
\hline & No $\mathrm{CHD}(n=33,970)$ & With CHD $(n=587)$ \\
\hline Median follow-up time (IQR) & $(3.82,12.00)$ & $\begin{array}{r}5.66 \\
(2.94,8.93 \\
\end{array}$ \\
\hline Age, range (years) & $30-74$ & $30-73$ \\
\hline Mean age, y & 44.70 & 51.91 \\
\hline \multicolumn{3}{|l|}{ Blood pressure, $(\mathrm{mm} \mathrm{Hg})$} \\
\hline Optimal and normal (SBP <130, DBP <85) & 60.06 & 47.53 \\
\hline High normal (SBP 130-139, DBP 85-89) & 16.18 & 19.76 \\
\hline $\begin{array}{l}\text { Stage I hypertension (SBP 140-159, DBP } \\
\text { 90-99) }\end{array}$ & 18.85 & 26.41 \\
\hline Stage II-IV hypertension (SBP $\geq 160, \mathrm{DBP} \geq 100$ ) & 4.90 & 6.30 \\
\hline \multicolumn{3}{|l|}{ Total cholesterol (mg/dL) } \\
\hline$<160$ & 9.44 & 3.92 \\
\hline $160-199$ & 34.62 & 19.59 \\
\hline $200-239$ & 36.60 & 40.37 \\
\hline $240-279$ & 14.88 & 27.60 \\
\hline$\geq 280$ & 4.46 & 8.52 \\
\hline \multicolumn{3}{|l|}{ High-density lipoprotein cholesterol (mg/dL) } \\
\hline$<35$ & 16.08 & 25.55 \\
\hline $35-59$ & 71.05 & 66.44 \\
\hline$\geq 60$ & 12.88 & 8.01 \\
\hline Diabetes & 1.47 & 4.60 \\
\hline Current smoker & 16.84 & 23.34 \\
\hline
\end{tabular}

Abbreviations: IQR = interquartile range; SBP, systolic blood pressure; DBP, diastolic blood pressure.

a The numbers are percentages unless otherwise stated.

${ }^{\mathrm{b}} \mathrm{X} 2$ test was performed to calculate statistical difference between the group with and without CHD. All comparisons were significant at $P<0.05$.

\footnotetext{
The opinions expressed by authors contributing to this journal do not necessarily reflect the opinions of the U.S. Department of Health and Human Services, the Public Health Service, the Centers for Disease Control and Prevention, or the authors' affiliated institutions.
} 
Table 3. Comparison Between Hazard Ratios for Coronary Heart Disease (CHD) Events for the Framingham Heart Study (FHS) Cohort and the Aerobics Center Longitudinal Study (ACLS) Cohort

\begin{tabular}{|c|c|c|c|c|c|c|}
\hline \multirow[t]{3}{*}{ Risk Factor } & \multirow{2}{*}{\multicolumn{2}{|c|}{ FHS $^{a}$}} & \multicolumn{4}{|c|}{ ACLS 12y Follow-up } \\
\hline & & & \multicolumn{2}{|c|}{ Unadjusted } & \multicolumn{2}{|c|}{ Fully Adjusted ${ }^{b}$} \\
\hline & HR & $95 \% \mathrm{Cl}$ & HR & $95 \% \mathrm{Cl}$ & HR & $95 \% \mathrm{Cl}$ \\
\hline Age, y & 1.05 & $1.04-1.06$ & 1.09 & $1.08-1.10$ & 1.09 & $1.08-1.10$ \\
\hline \multicolumn{7}{|l|}{ Blood pressure, $\mathrm{mm} \mathrm{Hg}$} \\
\hline $\begin{array}{l}\text { Optimal and normal (SBP }<130 \text {, } \\
\text { DBP <85) }\end{array}$ & \multicolumn{2}{|c|}{1.00 [Reference] } & \multicolumn{2}{|c|}{1.00 [Reference] } & \multicolumn{2}{|c|}{1.00 [Reference] } \\
\hline $\begin{array}{l}\text { High normal (SBP 130-139, } \\
\text { DBP 85-89 }\end{array}$ & 1.31 & $0.98-1.76$ & 1.66 & $1.33-2.06$ & 1.33 & $1.07-1.66$ \\
\hline $\begin{array}{l}\text { Stage I hypertension (SBP } \\
\text { 140-159, DBP 90-99) }\end{array}$ & 1.67 & $1.28-2.18$ & 1.95 & $1.60-2.38$ & 1.41 & $1.16-1.72$ \\
\hline $\begin{array}{l}\text { Stage II-IV hypertension (SBP } \\
\geq 160, \text { DBP } \geq 100 \text { ) }\end{array}$ & 1.84 & $1.37-2.06$ & 1.94 & $1.37-2.73$ & 1.23 & $0.87-1.74$ \\
\hline \multicolumn{7}{|l|}{ Total cholesterol (mg/dL) } \\
\hline$<160$ & 0.69 & $0.31-1.52$ & 0.77 & $0.49-1.21$ & 0.82 & $0.52-1.28$ \\
\hline 160-199 & \multicolumn{2}{|c|}{1.00 [Reference] } & \multicolumn{2}{|c|}{$1.00[$ Reference] } & \multicolumn{2}{|c|}{1.00 [Reference] } \\
\hline 200-239 & 1.77 & $1.25-2.50$ & 1.85 & $1.48-2.31$ & 1.59 & $1.27-1.99$ \\
\hline $240-279$ & 2.10 & $1.43-3.10$ & 2.90 & $2.28-3.68$ & 2.37 & $1.86-3.01$ \\
\hline$\geq 280$ & 2.29 & $1.39-3.76$ & 2.74 & $1.97-3.83$ & 2.21 & $1.59-3.09$ \\
\hline \multicolumn{7}{|c|}{ High density lipoprotein cholesterol (mg/dL) } \\
\hline$<35$ & 1.47 & $1.16-1.86$ & 1.59 & $1.32-1.92$ & 1.60 & $1.32-1.94$ \\
\hline $35-59$ & \multicolumn{2}{|c|}{1.00 [Reference] } & \multicolumn{2}{|c|}{$1.00[$ Reference $]$} & \multicolumn{2}{|c|}{ 1.00[Reference] } \\
\hline$\geq 60$ & 0.56 & $0.37-0.83$ & 0.66 & $0.49-0.90$ & 0.60 & $0.44-0.81$ \\
\hline Diabetes & 1.50 & $1.06-2.13$ & 3.45 & $2.34-5.07$ & 1.82 & $1.23-2.70$ \\
\hline Smoking status & 1.68 & $1.37-2.06$ & 1.60 & $1.32-1.93$ & 1.63 & $1.35-1.98$ \\
\hline
\end{tabular}

Abbreviations: HR, hazard ratio; $\mathrm{Cl}$, confidence interval; SBP, systolic blood pressure; DBP, diastolic blood pressure.

${ }^{a}$ Framingham Heart Study hazard ratios are from Wilson et al (10).

${ }^{\mathrm{b}}$ Fully adjusted model included age, blood pressure, total cholesterol, high density lipoprotein levels, diabetes diagnosis, and smoking status. 